Eelco F. M. Wijdicks

David K. Menon

Martin Smith

\section{Ten things you need to know to practice neurological critical care}

Received: 28 October 2014

Accepted: 29 October 2014

Published online: 15 November 2014

(C) Springer-Verlag Berlin Heidelberg and ESICM 2014

E. F. M. Wijdicks (『)

Division of Critical Care Neurology, Mayo Clinic, 200 First Street SW, MN, Rochester 55905, USA

e-mail: wijde@mayo.edu

D. K. Menon

Division of Anaesthesia, University of Cambridge, Box 93, Addenbrooke's Hospital, Cambridge CB2 2QQ, UK

\section{Smith}

Neurocritical Care Unit, National Hospital for Neurology and Neurosurgery, University College London Hospitals; UCLH/UCL National Institute for Health Research Biomedical Research Centre, London, UK

Care of the critically ill neurologic patient, more commonly referred to as neurocritical care, has matured through new knowledge [1], policy and administration [24], advances in imaging and monitoring techniques, and above all the introduction of neurointensivists and neuroscience intensive care units [5,6]. Different models of care exist but, whether provided in a specialist unit or within a general intensive care unit (ICU), the principles and standards of neurocritical care are identical. All three of us work in neurocritical care units and provide care for the most challenging patients on the edge of further deterioration. Our expertise is based on each of us having over 1,000 patient contacts annually for the past 1-2 decades. Here we share what we believe is importantand what worries us.

\section{Create a core group}

A well-run neurocritical care program should have several neurointensivists. Neurocritical care demands 24/7 staffing from teams with experience in managing neurological and neurosurgical emergencies. Neurocritical care teams must be familiar with the unique aspects of acute neurological disease processes and the effects of medical and surgical interventions on the injured brain, because the centrality of the nervous system is key.

\section{Build a collaborative practice}

Neurointensivists can only function in a multidisciplinary cooperative practice. The neurointensivist integrates contributions from neuroscience nursing staff, physical therapists, and pharmacists among many other health professionals. Specialized care should continue after discharge from the ICU; patients with an acute stroke need a multidisciplinary stroke service and patients surviving status epilepticus need an epilepsy specialist.

\section{Stabilize acute brain injury by minimizing secondary insults}

Acute brain injury is followed by a host response which results in waves of subsequent biochemical and inflammatory processes. Some initiating injuries (such as trauma) are not amenable to direct therapy, but others can be (such as ischemic stroke). Early aggressive intervention to minimize secondary insults, however, improves the outcome trajectory in many patients $[7,8]$. Increased intracranial pressure, mass effect, and brain shift, but also systemic complications as elementary as fever, 
hypotension, hypoxemia, and hyperglycemia, must be treated. Hypo-osmolar fluids, excessive sedation, and surgical procedures that can wait (e.g., tracheostomy) should be avoided. It is important to get the little things right-neurocritical care is as much about meticulous systemic physiological optimization as about specific brain-directed therapies.

\section{Recognize the importance of deterioration}

Patients are stable until they are not. Tissue destruction caused by acute injury is worsened by ongoing insults, which need early recognition and treatment. Foremost, recognition of clinical deterioration requires a detailed neurological examination. Deterioration from intracranial changes, such as swelling from large territorial infarcts, expansion of intracranial hematomas, new appearance of contusions and traumatic brain edema, and recurrent seizures or status epilepticus, require immediate intervention [9].

\section{Interpret neuroimaging and neuromonitoring}

Static and perfusion CT and MR scans and cerebral angiography provide important diagnostic information. There may be a disconnect between neuroimaging findings and clinical condition, and substantial clinical acumen is required to determine clinical management. Finding the most appropriate study for a particular clinical scenario is a skill. It remains unclear whether monitors of cerebral physiology can detect potential problems but they are used to supplement clinical monitoring. There is an expectation that reliable noninvasive brain monitoring will emerge.

\section{Consult with neurosurgery and interventional neuroradiology}

Acute neurosurgical intervention (decompressive craniectomy or mass evacuation) can salvage a patient who rapidly deteriorates from brain tissue shift and brainstem displacement, and placement of a ventriculostomy must be immediate in acute hydrocephalus. Time to surgery determines the postoperative outcome. Consultation with interventional neuroradiology allows collaborative decisions about clot retrieval after acute ischemic stroke and treatment options in diffuse cerebral vasospasm in subarachnoid hemorrhage.

\section{Appreciate the importance of systemic complications}

Organs may fail from a sympathetic surge that can cause neurogenic pulmonary edema, stress cardiomyopathy, gastric erosions, and a more general endocrinopathy.

Common medical complications in patients with acute brain injury are shown in Fig. 1. Patients with an abnormal level of consciousness cannot protect their airway, but not all patients will need to be intubated. Likewise patients who are intubated may need a tracheostomy, but not all patients require a tracheostomy. Patients with acute neuromuscular respiratory failure may need intubation but some can be treated with noninvasive mechanical ventilation. Neurointensivists must have a good understanding of indications for intubation and weaning from mechanical ventilation so that respiratory support is determined based on the nature of acute neurologic disease.

\section{Identify neuroemergencies elsewhere}

Major neurologic problems occur in many hospital locations and neurointensivists are in a good position to expand their role outside the neurosciences ICU. They may assist in triage and resuscitation in the emergency department [10] and provide ICU consultation for the assessment of coma, assist with evaluation and management of delirium, treat intractable seizures, and identify a neuromuscular disorder in a patient not weaning from mechanical ventilation.

\section{Look at the quality of survival, not just survival}

To determine proportionality in care requires experience and seniority. The basic tenet is to treat acute problems as aggressively as possible, since minimizing second insults will minimize residual disability. This approach will inevitable mean that we occasionally avoid death at the expense of survival with very severe disability. This tension demands careful clinical judgment that takes account 
Fig. 1 Major medical problems in patients with acute brain injury (from Wijdicks (C) 2014 by Mayo Foundation for Medical Education and Research) [15]

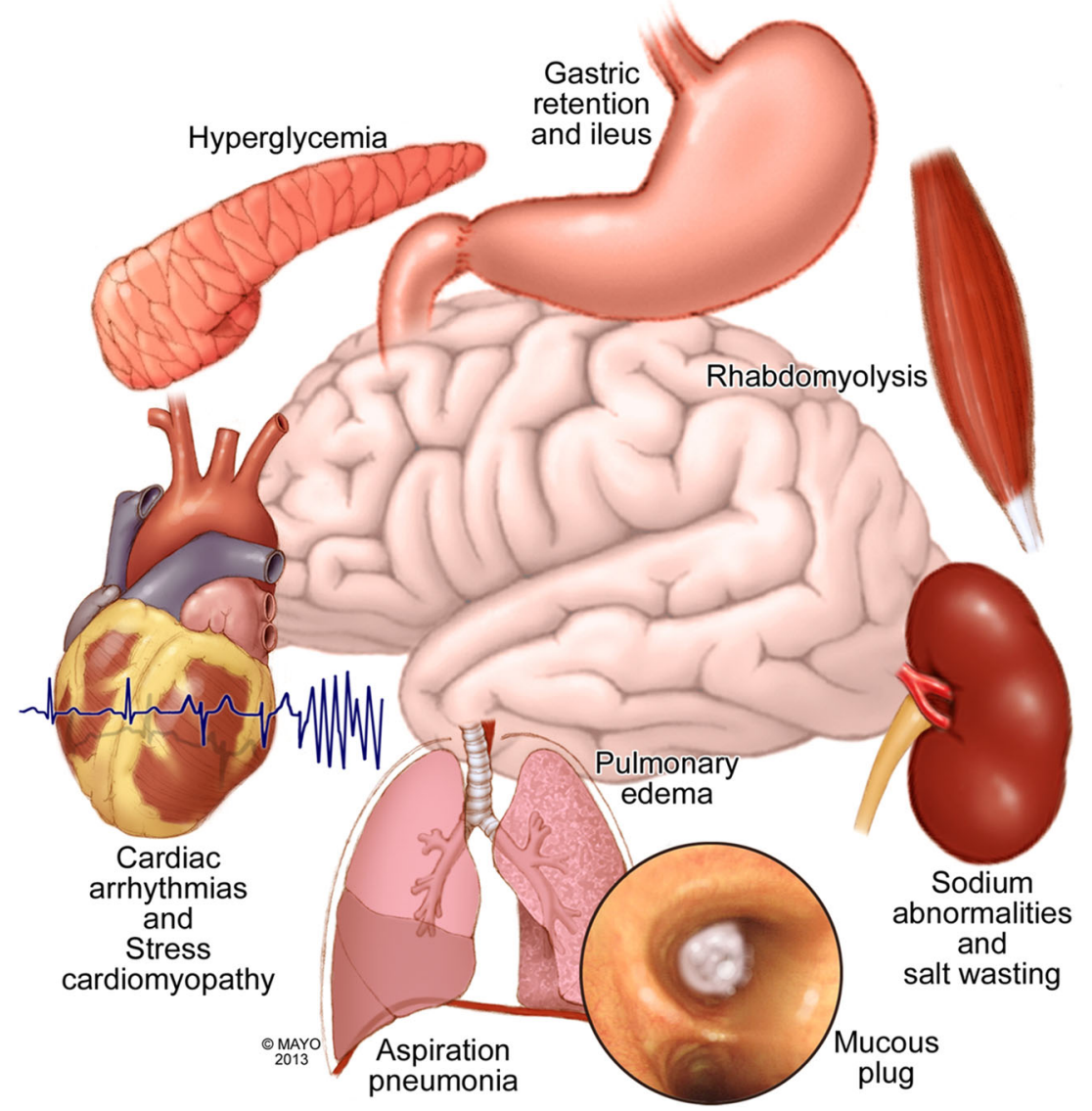

of any wishes individual patients may have expressed before their acute illness. Withdrawing treatment too early may ignore the potential for neurorehabilitation to an eventual acceptable outcome in patients who leave the ICU in a severely disabled state. However, it is clear that some patients are at a breaking point and face impossible odds, and aggressive early treatment should be linked (where appropriate) to compassionate end-of-life care if a satisfactory degree of clinical improvement does not occur within an appropriate time scale.

\section{Connect with the family of the patient}

Communication with family members is a crucial and time-consuming role of the neurointensivist. Unlike in general intensive care, where communication with the patient may be possible, family members of brain-injured patients must routinely act as patient surrogates and share decision-making with the clinical team. Extensive discussions are necessary to reach the right decision for an individual patient. The support of the family is often in our hands and a patient's troubled family remains on our mind even when we go home.

\section{A final word}

Neurologic critical care is perhaps the most exciting new subspecialty in the neurosciences and intensive care medicine. It is more than conceivable that patients cared for in a neurocritical care unit may have a better outcome [11-13], and we must move past the fact that neuroscience patients can be managed by generalists. Training programs in neurocritical care have been established in multiple parts of the world [14]. 


\section{References}

1. Wijdicks EFM (2014) The journal and its first decade. Neurocrit Care 20:1-2

2. Ward MJ, Shutter LA, Branas CC, Adeoye O, Albright KC, Carr BG (2012) Geographic access to US neurocritical care units registered with the Neurocritical Care Society. Neurocrit Care 16:232-240

3. Diringer MN, Bleck TP, Claude Hemphill J 3rd, Menon D, Shutter L, Vespa P, Bruder N, Connolly ES Jr, Citerio G, Gress D, Hanggi D, Hoh BL, Lanzino G, Le Roux P, Rabinstein A, Schmutzhard E, Stocchetti N, Suarez JI, Treggiari M, Tseng MY, Vergouwen MD, Wolf S, Zipfel G (2011) Critical care management of patients following aneurysmal subarachnoid hemorrhage: recommendations from the Neurocritical Care Society's Multidisciplinary Consensus Conference. Neurocrit Care 15:211-240

4. Le Roux P, Menon DK, Citerio G, Vespa P, Bader MK, Brophy GM, Diringer MN, Stocchetti N, Videtta W, Armonda R, Badjatia N, Boesel J, Chesnut R, Chou S, Claassen J, Czosnyka M, De Georgia M, Figaji A, Fugate J, Helbok R, Horowitz D, Hutchinson P, Kumar M, McNett M, Miller C, Naidech A, Oddo M, Olson D, O'Phelan K, Provencio JJ, Puppo C, Riker R, Robertson C, Schmidt M, Taccone F (2014) Consensus summary statement of the International Multidisciplinary Consensus Conference on Multimodality Monitoring in Neurocritical Care. A statement for healthcare professionals from the Neurocritical Care Society and the European Society of Intensive Care Medicine. Neurocrit Care. doi: 10.1007/s12028-0041-5
5. Korbakis G, Bleck T (2014) The evolution of neurocritical care. Crit Care Clin 30:657-671

6. Wijdicks EFM, Worden WR, Miers A, Piepgras DG (2011) The early days of the neurosciences intensive care unit. Mayo Clin Proc 86:903-906

7. Smith M (2008) Monitoring intracranial pressure in traumatic brain injury. Anesth Analg 106:240-248

8. English SW, Turgeon AF, Owen E, Doucette S, Pagliarello G, McIntyre L (2013) Protocol management of severe traumatic brain injury in intensive care units: a systematic review. Neurocrit Care 18:131-142

9. Lindgren $\mathrm{C}$, Nordh E, Naredi S, Olivecrona M (2012) Frequency of nonconvulsive seizures and non-convulsive status epilepticus in subarachnoid hemorrhage patients in need of controlled ventilation and sedation. Neurocrit Care 17:367-373

10. Smith WS, Weingart S (2012) Emergency neurological life support (ENLS): what to do in the first hour of a neurological emergency. Neurocrit Care 17(Suppl 1):S1-S3

11. Kramer AH, Zygun DA (2011) Do neurocritical care units save lives? Measuring the impact of specialized ICUs. Neurocrit Care 14:329-333
12. Damian MS, Ben-Shlomo Y, Howard R, Bellotti T, Harrison D, Griggs K, Rowan K (2013) The effect of secular trends and specialist neurocritical care on mortality for patients with intracerebral haemorrhage, myasthenia gravis and Guillain-Barre syndrome admitted to critical care: an analysis of the Intensive Care National Audit and Research Centre (ICNARC) national United Kingdom database. Intensive Care Med 39:1405-1412

13. Burns JD, Green DM, Lau H, Winter M, Koyfman F, DeFusco CM, Holsapple JW, Kase CS (2013) The effect of a neurocritical care service without a dedicated neuro-ICU on quality of care in intracerebral hemorrhage. Neurocrit Care 18:305-312

14. Dyson EW, Kolias AG, Burnstein RM, Hutchinson PJ, Garnett MR, Menon DK, Trivedi RA (2014) Neuro-critical care: a valuable placement during foundation and early neurosurgical training. Br J Neurosurg 28:675-679

15. Wijdicks EFM (2014) Providing acute care. Oxford University Press, New York 